\title{
Everolimus in kidney transplantation
}

This article was published in the following Dove Press journal:

Transplant Research and Risk Management

7 July 2011

Number of times this article has been viewed

\section{James E Cooper'}

Uwe Christians ${ }^{2}$

Alexander C Wiseman'

'Division of Renal Diseases and Hypertension, Transplant Center, ${ }^{2} \mathrm{C} 42$ Integrated Solutions in Systems Biology for Clinical Research and

Development, University of Colorado

Denver, Aurora, CO, USA
Correspondence: Alexander Wiseman Transplant Center, University of Colorado Denver Health Sciences Center, Mail Stop F749, AOP 7089, 1635 North Aurora Court, Aurora, CO 80045, USA $\mathrm{Tel}+\mathrm{I} 7208480860$

Fax +l 7208482238

Email alexander.wiseman@ucdenver.edu
Abstract: Everolimus is a novel target of rapamycin (mTOR)-I analog that has recently been approved in combination with cyclosporine A and steroids for use in the prevention of organ rejection in kidney transplant recipients. Compared with rapamycin, everolimus is characterized by a shorter half-life and improved bioavailability. Prior to US Food and Drug Administration approval, a number of Phase II and III clinical trials were undertaken to evaluate the effectiveness of everolimus in combination with calcineurin inhibitors for preventing acute rejection and promoting allograft survival in kidney transplant recipients. In this report, we review the pharmacokinetic properties of everolimus, the clinical efficacy studies that led to its approval for use in kidney transplantation, as well as reported data on patient safety and tolerability associated with its use.

Keywords: mTOR inhibitors, kidney transplantation, everolimus

\section{Introduction}

Identification of the potent immunosuppressive properties characteristic of sirolimus 20 years after its discovery as an antifungal and antitumor agent on Easter Island in 1969 has led to widespread interest in mammalian targets of rapamycin inhibitors (mTOR-Is) as potential maintenance therapy for kidney transplant recipients. The relative lack of nephrotoxicity associated with chronic mTOR-I use has generated further hope that these agents could either lessen the burden or replace calcineurin inhibitors altogether, which are well known to be effective immunosuppressants but have considerable potential for chronic nephrotoxicity. Everolimus is a novel structural analog of sirolimus designed to improve oral bioavailability, and has been approved by the US Food and Drug Administration for use in advanced renal cell carcinoma, subependymal giant cell astrocytoma, and drug-eluting coronary stents. Everolimus was previously approved in Europe for use in adult kidney and heart transplant recipients and in the US in combination with reduced-dose calcineurin inhibitors and steroids for adult recipients at low-to-moderate risk in 2010. In this review, we discuss the pharmacodynamic and pharmacokinetic properties of everolimus, the clinical trials of efficacy in kidney transplant recipients, as well as the safety and tolerability profiles associated with its use.

\section{Background}

Kidney transplantation remains the only curative option for end-stage renal disease, and offers both quality of life and survival benefits over chronic dialysis. ${ }^{1,2}$ The evolution 
of immunosuppression protocols for kidney transplant recipients over the last five decades has resulted in dramatic improvements in acute rejection rates and allograft survival. The introduction of the calcineurin inhibitor, cyclosporine A, in the early 1980 s gave rise to possibly the most striking improvement in graft outcomes, lowering acute rejection rates by half and increasing 1-year graft survival from 50\% to over $80 \%$ compared with the previous azathioprine/prednisone era. ${ }^{3}$ In current practice, tacrolimus in combination with Cellcept ${ }^{\circledR}$ (mycophenolate mofetil) or mycophenolic acid accounts for over $80 \%$ of post-kidney transplant immunosuppression regimens in the US, and is associated with a 1 -year graft survival rate of $91 \%-95 \%{ }^{4}$

While widespread use of the calcineurin inhibitors, cyclosporine A and tacrolimus, has had an important role in the improved short-term graft outcomes of the more recent eras, the nephrotoxic nature of these immunosuppressants results in considerable potential for chronic graft damage. ${ }^{5}$ With little improvement in long-term graft outcomes in recent years, ${ }^{6,7}$ there has been more focus on identifying less nephrotoxic options for chronic maintenance immunosuppression. Identification of the mammalian target of rapamycin inhibitor (mTOR-I), sirolimus, as a potent immunosuppressant with minimal nephrotoxicity has led to numerous clinical trials investigating its use in a variety of calcineurin inhibitor minimization strategies, including withdrawal, ${ }^{8}$ early conversion, ${ }^{9}$ late conversion, ${ }^{10}$ and complete avoidance. ${ }^{11}$

Despite these efforts, the use of sirolimus in kidney transplant maintenance immunosuppression regimens has remained limited due to concerns regarding efficacy, side effects, and patient tolerability. The mTOR-I, everolimus, was first described in 1997 as a structural analog of sirolimus. ${ }^{12}$ Both sirolimus and everolimus are only available as oral formulations, and compared with sirolimus, everolimus has improved solubility, $60 \%$ greater bioavailability, a shorter half-life (28 vs 60 hours), and more rapid achievement of steady-state levels (4 vs 6 days). ${ }^{12-14}$ Preclinical studies have demonstrated an immunosuppressive synergism between everolimus and cyclosporine $\mathrm{A},{ }^{15}$ and clinical trials have therefore largely focused on the efficacy of everolimus in combination with various doses of cyclosporine A. These studies will be described in detail following a summary of the mechanism of action and pharmacological properties of everolimus.

\section{Mechanism of action}

As a first step, everolimus binds to its intercellular target, the immunophilin FK506-binding protein 12 (FKBP12), which also binds tacrolimus. However, instead of inhibiting calcineurin like the tacrolimus-FKBP12 complex, the everolimus-FKBP12 complex inhibits mTOR, which causes an arrest in the G1 cell cycle. ${ }^{16}$ mTOR belongs to the phospho-inositide 3-kinase-related protein kinase family, and its signaling pathway couples energy and nutrient abundance to the execution of cell growth and division, owing to the ability of TOR protein kinase to simultaneously sense energy, nutrients, stress, and growth factors. ${ }^{16}$ Mammalian TOR complex 1 (mTORC1) and mTORC2 exert their actions by regulating other important kinases, such as S6 kinase and Akt. At therapeutically relevant concentrations, the everolimus-FKBP12 complex mainly inhibits mTORC1 and thus inactivates the p70 S6 kinase in lymphocytes, resulting in selective inhibition of the synthesis of ribosomal proteins and thus immunosuppression. ${ }^{17,18}$ Everolimus has a 2.1-fold weaker binding affinity for FKBP12 than sirolimus. ${ }^{16} \mathrm{X}$-ray crystallographic studies of the FKBP12-everolimus complex have revealed a three-dimensional structure very similar to that of the FKBP12-sirolimus complex. ${ }^{19,20}$ However, the lower binding affinity to FKBP12 can be explained by the fact that $\mathrm{C}(40)$ alkylation disrupts the hydrogen bond existing between the FKBP12-sirolimus complex and between the $\mathrm{C}(40)$ hydroxyl and the Gln-53 main chain carbonyl. ${ }^{16}$ Accordingly, everolimus inhibition of interleukin-6-stimulated lymphocyte proliferation was found to be 2.5-fold weaker than sirolimus. ${ }^{16}$ Figure 1 illustrates the structural difference between everolimus and sirolimus.

\section{Pharmacokinetics}

One rationale for developing everolimus was its higher oral bioavailability compared with sirolimus. ${ }^{16}$ A study in rats showed the oral bioavailability of everolimus to be $16 \%$, and thus higher than that of sirolimus (10\%). ${ }^{13}$ Everolimus and sirolimus are substrates for $\mathrm{P}$ glycoprotein-like-mediated efflux transporters in the intestine. However, sirolimus is also partially removed from cells by a second efflux system that does not interact with everolimus, ${ }^{21}$ and it can be speculated that this is one of the reasons for the better oral bioavailability of everolimus.

Another major difference between sirolimus and everolimus is the shorter terminal half-life of the latter. Depending on the patient population studied (healthy individuals or transplant patients) the average half-life of everolimus is 18-35 hours vs 60 hours for sirolimus. ${ }^{22}$ As a result of this shorter half-life, as well as development aimed at coprescription with cyclosporine A, everolimus is dosed twice daily. The shorter half-life of everolimus has several clinical 


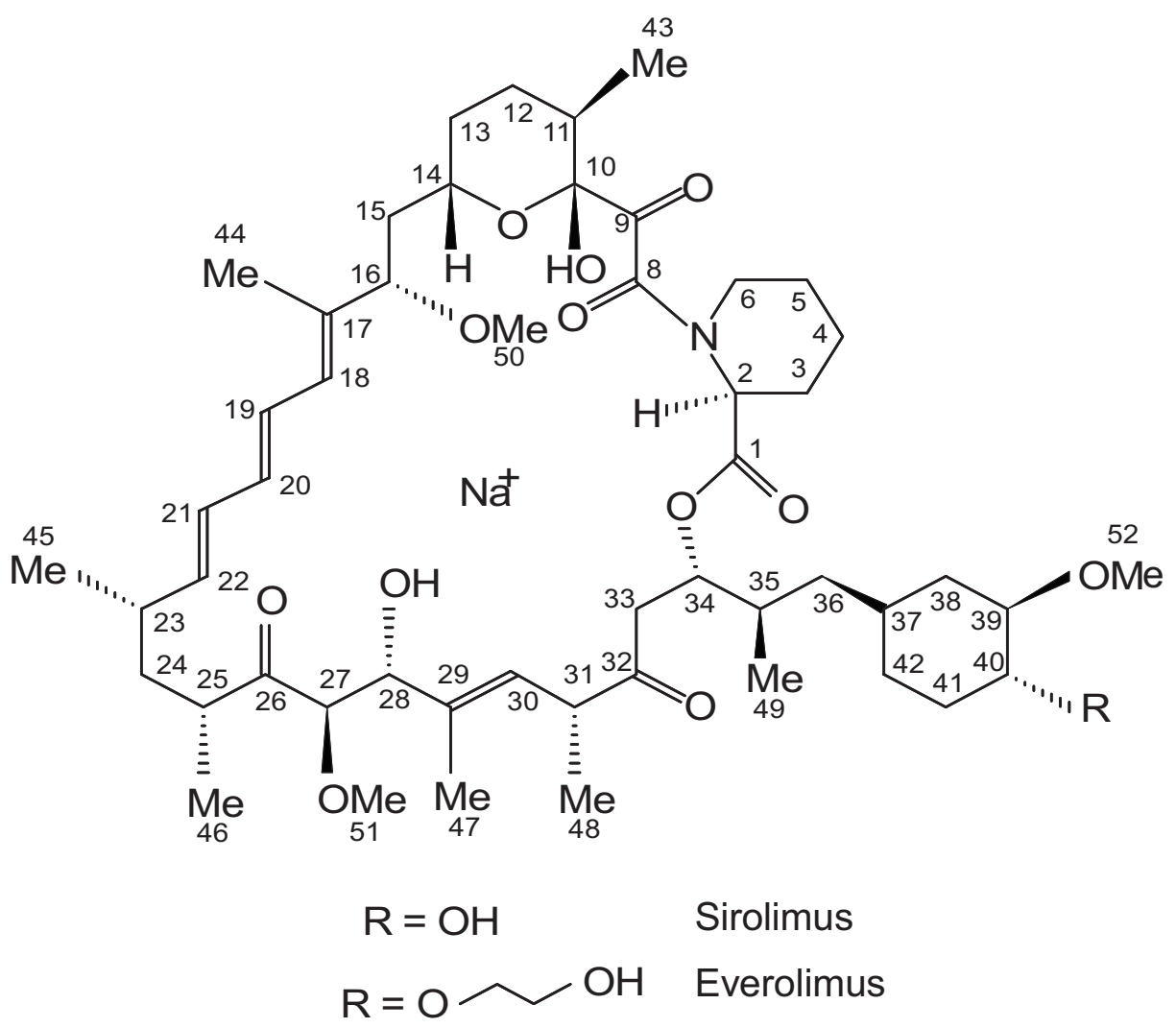

Figure I Comparison of the structures of everolimus and sirolimus. Atom numbering follows the International Union of Pure and Applied Chemistry nomenclature

advantages, ie, no loading dose is necessary for everolimus, the steady state is reached faster, and the drug is eliminated more rapidly, translating into a more rapid patient response after dose change. Dose adjustments of everolimus should be based on trough concentrations obtained 4-7 days after a previous dosing change. ${ }^{22}$

The clinical pharmacokinetics of everolimus have been reviewed in detail. ${ }^{22}$ Everolimus is rapidly absorbed, and peak concentrations are reached after 1.3-1.8 hours. ${ }^{23,24}$ Steady-state peak and trough concentrations, as well as areas under the concentration-time curve (AUC) are proportional to dosage. In blood, everolimus is $>75 \%$ protein-bound, ${ }^{23}$ and distributes more than $75 \%$ into blood cells. Thus, as is the case for cyclosporine A, tacrolimus, and sirolimus, everolimus is generally not removed by dialysis, and ethylenediamine tetra-acetic acid whole blood is used for therapeutic drug monitoring. ${ }^{22}$

\section{Metabolism and elimination}

Everolimus is extensively metabolized in the small intestine and liver and, as aforementioned, $98 \%$ of the drug is eliminated via bile in the form of metabolites. ${ }^{22}$ Most of the known metabolites are the product of oxidative metabolism generated by cytochrome P450 (CYP)3A4 and CYP3A5 enzymes, resulting in hydroxylated and/or demethylated metabolites (Figure 2B) ${ }^{25} \mathrm{~A}$ minor metabolic pathway in adults is via CYP2C8, which is potentially of greater importance in young children. ${ }^{26,27}$ A unique phosphocholine ester metabolite has also been identified that shows good binding to FKBP12, but only weak inhibition of mTOR. ${ }^{28}$ The structures of the major metabolites generated after incubation of everolimus with human liver microsomes are shown in Figure 2A. Based on the published literature, none of these metabolites seems to retain more than $10 \%$ of the immunosuppressive activity of everolimus. ${ }^{29}$ In contrast with sirolimus, for which 39-O-desmethy sirolimus is the major metabolite in blood, 46-OH everolimus is the major metabolite of everolimus in blood. Demethylation at the $\mathrm{C}(39)$ position is inhibited by the $\mathrm{C}(40)$ modification that differentiates everolimus and sirolimus $^{30}$ (Figure 1), thus leading to a marked difference in the metabolite patterns for everolimus and sirolimus in blood. Interestingly, sirolimus is not a clinically relevant metabolite of everolimus. ${ }^{25}$ This can be explained by molecular dynamics and quantum chemical calculations. ${ }^{30}$

\section{Specific populations}

The pharmacokinetics of everolimus did not differ according to age, gender, or weight in adults. ${ }^{24,31}$ The apparent clearance 


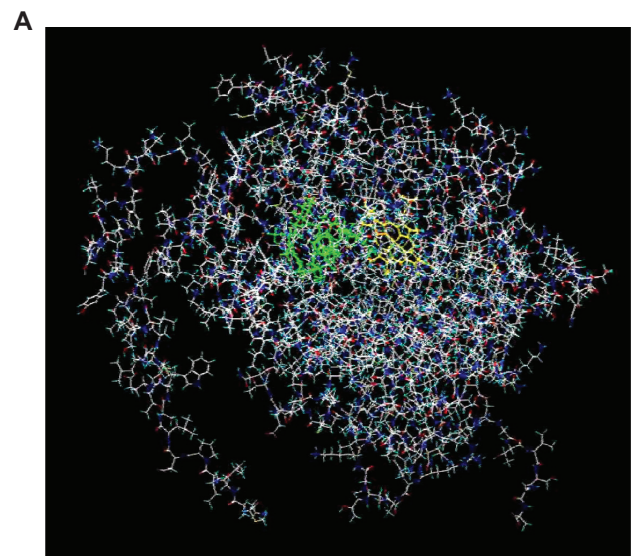

B

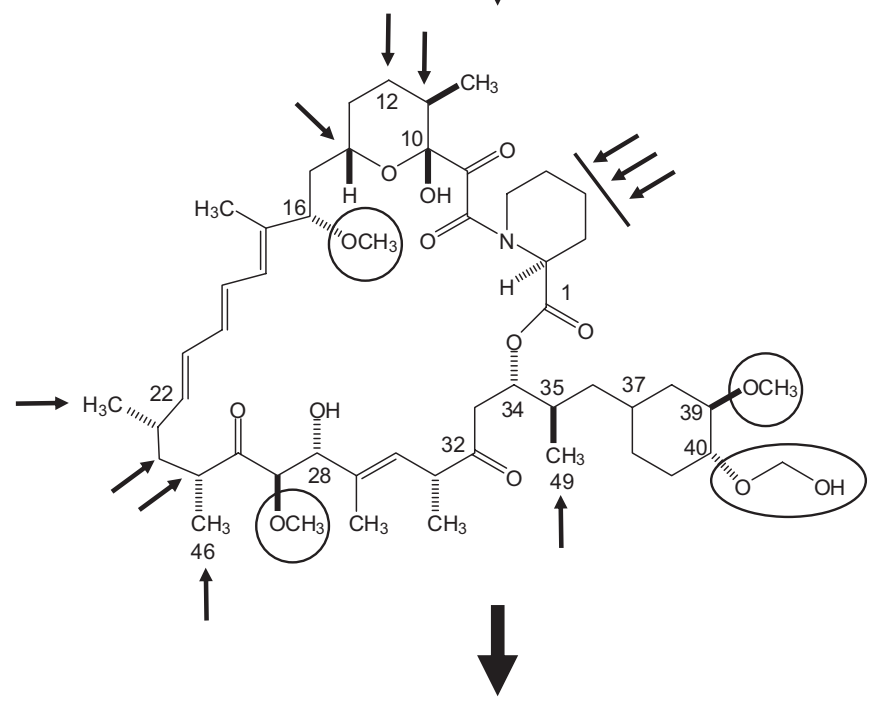
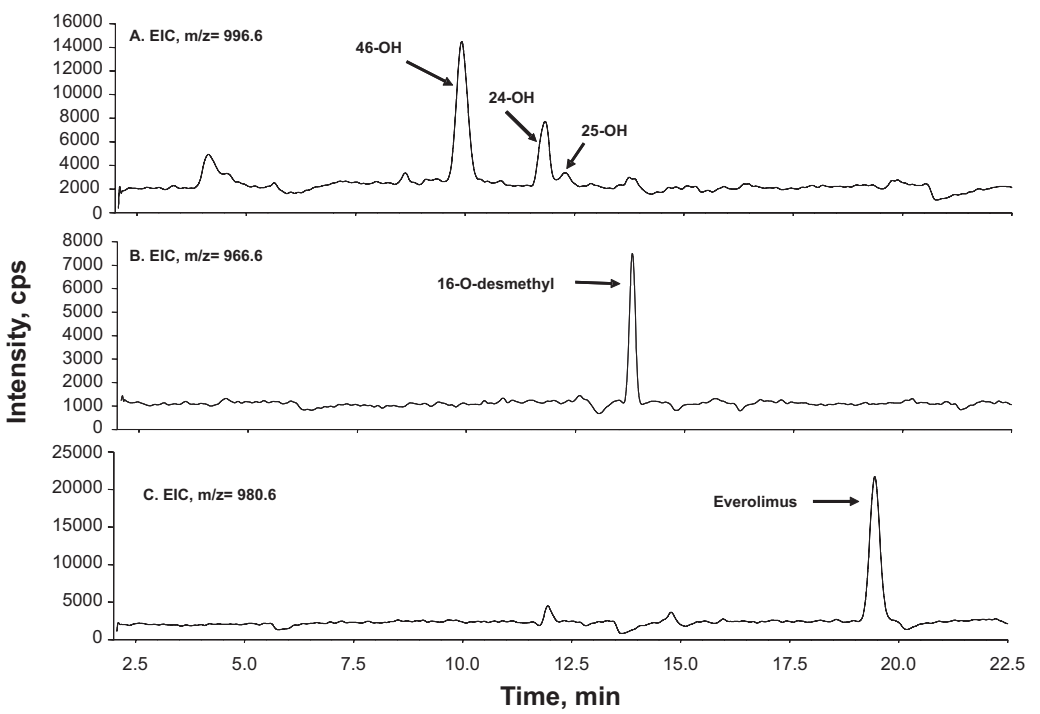

Figure 2 Drug metabolism of everolimus. A) Computer simulation of everolimus in the human cytochrome P450 3A4 enzyme. The green structure is everolimus, the yellow the heme portion of the cytochrome P450 3A enzyme that is responsible for oxidation. ${ }^{30} \mathbf{B}$ ) Shows the resulting metabolites identified after in vitro metabolism of everolimus by human liver microsomes. ${ }^{25,55}$ Hydroxylation positions are marked by arrows and O-demethylation and O-hydroxyethylation positions are circled. Please note that there were three metabolites identified with hydroxylations at the piperidine ring. These could be separated by high-performance liquid chromatography indicating monohydroxylation at different positions at the piperidine ring but the exact structures could not be identified. C) Representative high-pressure liquid chromatography-mass spectrometry ion chromatogram showing a typical everolimus metabolite pattern in the blood of a kidney transplant patient. ${ }^{118}$ 
for a representative patient, 44 years old and weighing $71 \mathrm{~kg}$, was $8.82 \mathrm{~L} /$ hour. $^{22} \mathrm{~A} 1 \mathrm{~kg}$ increase in bodyweight resulted in a $0.44 \%$ increase in apparent clearance. ${ }^{31}$

In de novo renal transplant recipients receiving cyclosporine A, corticosteroids, and everolimus, Asian ethnicity did not significantly affect apparent everolimus clearance. In contrast, apparent clearances were on average $20 \%$ higher in African-American patients than in nonblack patients, ${ }^{31}$ likely due to more frequent expression of CYP3A5 in the intestine and liver of African-Americans, as well as the highly polymorphic nature and variable distribution of $\mathrm{P}$ glycoprotein among ethnic groups. ${ }^{32}$ There are no well-controlled studies establishing the safety of everolimus during pregnancy. While the safe and effective use of everolimus in pediatric populations has not been adequately studied, current data indicate that body weight-adjusted dosages are necessary in children. ${ }^{22}$ Sirolimus undergoes different metabolism in children younger than 2 years of age compared with older children and adults, and thus it is reasonable to expect similar findings with everolimus. ${ }^{26}$ The pharmacokinetics of everolimus do not seem to be affected by kidney function, ${ }^{33}$ which is not surprising given that more than $98 \%$ of everolimus is eliminated in the form of metabolites via bile. ${ }^{22}$ Although it has been stated that everolimus is not altered in patients with mild to moderate hepatic impairment (Child-Pugh Classes A and B), ${ }^{33}$ there is evidence that its clearance is significantly reduced (by $53 \%$ ) in individuals with moderate hepatic impairment compared with healthy individuals $(9.1 \pm 3.1 \mathrm{~L} /$ hour vs $19.4 \pm 5.8 \mathrm{~L} /$ hour $) .{ }^{34}$ Based on these data, the authors recommended a reduction of everolimus dose by $50 \%$ in patients with Child-Pugh Class B liver function impairment. ${ }^{22,34}$ The effect of severe hepatic impairment (Child-Pugh Class C) on everolimus pharmacokinetics remains to be established. ${ }^{33,34}$

\section{Pharmacokinetic variability: \\ Pharmacogenomics, drug-drug, food-drug, and disease-drug interactions}

Everolimus meets the criteria of a narrow therapeutic index drug as defined by regulatory agencies and, as such, requires therapeutic drug monitoring and dosing guided by blood concentrations. ${ }^{22,33}$ By definition, approved drugs with narrow therapeutic indices typically exhibit small intrasubject variability. ${ }^{35}$ However, everolimus shows significant interindividual differences that most likely involve genetic polymorphisms of drug-metabolizing enzymes and active transporters, such as CYP3A5 and P glycoprotein, ${ }^{32,36}$ which are critical for the first-pass effect, pharmacokinetics, and elimination of everolimus. Because more than $50 \%$ of all clinically relevant drugs (including immunosuppressants such as cyclosporine A, tacrolimus, and prednisone) are substrates of these proteins, there is the potential for a multitude of competitive and noncompetitive drugdrug interactions. A 6-month pharmacokinetic study in patients receiving everolimus and cyclosporine A reported trough everolimus concentrations of $4.3 \pm 2.4 \mathrm{ng} / \mathrm{mL}$ and $7.2 \pm 4.2 \mathrm{ng} / \mathrm{mL}$ for $0.75 \mathrm{mg}$ and $1.5 \mathrm{mg}$ twice-daily doses, respectively. ${ }^{37}$ As such, the starting dose of everolimus for most patients is $0.75 \mathrm{mg}$ twice daily in combination with a calcineurin inhibitor to achieve a therapeutic concentration of 3-8 ng/mL. ${ }^{33,38,39}$ Whereas both everolimus and sirolimus blood concentrations are increased by cyclosporine $\mathrm{A},{ }^{37,40-42}$ they are only minimally affected by tacrolimus. ${ }^{43-45}$ Nevertheless, a starting everolimus dose of $0.75 \mathrm{mg}$ twice daily in combination with tacrolimus resulted in mean trough everolimus concentrations consistently greater than $3 \mathrm{ng} / \mathrm{mL}$ over 6 months in the US09 study described below. ${ }^{46}$ Coadministration of inhibitors of CYP3A and P glycoprotein may increase systemic everolimus exposure and thus the risk of everolimus toxicity, while inducers may lead to lower blood everolimus concentrations and a reduction in immunosuppressive activity. Everolimus drug-drug interactions have been reviewed in detail elsewhere. ${ }^{22}$

In a single-dose study in healthy individuals, a highfat meal delayed the time to maximum concentration of everolimus by a median 1.25 hours, reduced peak blood concentration by $60 \%$, and reduced the AUC by $16 \% .{ }^{47}$ To minimize longitudinal variability in exposure, everolimus should be administered consistently either with or without food. Another concern is foods, food supplements, and herbs that contain compounds which are inhibitors or inducers of CYP3A enzymes and P glycoprotein. Representative examples are grapefruit juice ${ }^{33}$ that markedly increases oral bioavailability through reducing the activity of intestinal drug-metabolizing enzymes ${ }^{48}$ and hyperforin, the active compound of St John's wort, that induces CYP3A and P glycoprotein via the steroid $\mathrm{X}$ receptor, resulting in reduced drug exposure and efficacy. ${ }^{49}$

Knowledge of disease-drug interactions is still surprisingly incomplete. The activity of CYP3A is reduced by high intracellular free radical concentrations, infectious diseases, inflammation, and immune reactions, ${ }^{50,51}$ and the activity of ATP-binding cassette transporters, such as $\mathrm{P}$ glycoprotein, is affected in similar ways. ${ }^{52}$ The overall effect of inflammation is increased exposure to drugs and/or their metabolites due to a reduced first-pass effect 
and inhibited hepatic elimination. This leads to reduced dosage requirements. ${ }^{53}$ Although disease-drug interactions of everolimus have not specifically been studied as yet, it is reasonable to expect that these also contribute to the intraindividual pharmacokinetic variability of everolimus.

\section{Therapeutic drug monitoring}

Routine whole blood therapeutic everolimus concentration monitoring to guide dosing of individual patients is recommended and, as discussed below, the recommended therapeutic range for trough blood concentrations is $3-8 \mathrm{ng} / \mathrm{mL}$ in combination with calcineurin inhibitors and steroids. ${ }^{22,33}$ Steady-state trough everolimus concentrations are correlated with the AUC $\left(r^{2}=0.88\right)$, indicating that measuring trough blood concentrations is a valid approach to therapeutic drug monitoring. ${ }^{24}$ There are three major analytical strategies for clinical therapeutic drug monitoring of everolimus, ie, immunoassay, high-performance liquid chromatography (HPLC)/ultraviolet light (UV) and HPLC-mass spectrometry. An immunoassay is presently available outside of the US, but as is not uncommon for immunoassays for therapeutic drug monitoring of immunosuppressants, it overestimates everolimus concentrations, partially due to cross-reactivity of the antibody with the less active everolimus metabolites. ${ }^{54,55}$ An improved version of this immunoassay is under development. HPLC/UV assays for the quantification of everolimus are described, but are prone to interference and their sensitivity is limited. In general, HPLC-mass spectrometry is considered the gold standard, because it is specific for everolimus and, compared with immunoassays and HPLC/UV, has superior sensitivity with lower limits of quantitation, usually in the $\mathrm{pg} / \mathrm{mL}$ range. For a more detailed review, please refer to Korecka and Shaw. ${ }^{56}$ Currently, due to the limitations of the available everolimus immunoassay, more than $50 \%$ of all laboratories are using HPLC-based assays for clinical therapeutic drug monitoring of everolimus. ${ }^{57}$

\section{Efficacy studies}

The ability of everolimus to prevent acute rejection was first demonstrated in preclinical models of kidney, heart, and lung transplantation. ${ }^{58-60}$ In addition to preventing acute rejection, everolimus has been shown to prevent manifestations of chronic renal allograft injury in rats, including glomerulosclerosis and proteinuria, likely via suppression of growth factors. ${ }^{61}$ Vascular remodeling, another frequent manifestation of chronic allograft damage, is diminished by everolimus through inhibition of vascular smooth muscle cell proliferation. ${ }^{62}$ In vitro and animal studies indicate that everolimus may also have the potential to antagonize several toxicities of low-dose calcineurin inhibitors. ${ }^{63}$ Because the role of calcineurin inhibitors in chronic allograft damage has become more evident in the last decade, the apparent ability of everolimus to protect allografts from both acute rejection as well as chronic lesions has made it an attractive target for clinical efficacy studies. The following sections describe efficacy data from clinical trials investigating the combination of various doses of everolimus with full-dose or reduced-dose calcineurin inhibitors in de novo kidney transplant recipients. In all cases, cyclosporine A refers to the modified cyclosporine preparation $\left(\mathrm{Neoral}^{\circledR}\right.$, Novartis Pharmaceuticals, Basal, Switzerland), with trough level monitoring performed on whole blood samples.

\section{Studies B20I and B25I: Everolimus + full-dose cyclosporine A}

The B201 study was a multicenter, 36-month equivalence trial comparing two fixed doses of everolimus with mycophenolate mofetil + full-dose cyclosporine A. ${ }^{64,65}$ This trial was double-blinded until 12 months after enrollment, and included 588 patients randomized 1:1:1 to either low-dose everolimus (1.5 mg/day), high-dose everolimus ( $3 \mathrm{mg} /$ day), or mycophenolate mofetil $2 \mathrm{~g} /$ day. All three arms received steroids and cyclosporine $\mathrm{A}$, with goal trough levels of $150-400 \mathrm{ng} / \mathrm{mL}$ during post-transplant weeks $1-4$, and 100-300 ng/mL thereafter. However, after an analysis of data from the 12-month double-blind phase in January 2001 revealed suboptimal renal function in both everolimus groups, an amendment was made to the protocol allowing for a reduction in cyclosporine A trough levels to $50-75 \mathrm{ng} / \mathrm{mL}$ in patients with trough everolimus concentrations above $3 \mathrm{ng} / \mathrm{mL}$.

The primary endpoint of efficacy failure at 6 months included biopsy-proven acute rejection, graft loss, death, or loss to follow-up, and was reached by similar proportions of patients in each group, ie, $26.8 \%$ for everolimus $1.5 \mathrm{mg} / \mathrm{day}$, $26.3 \%$ for everolimus $3 \mathrm{mg} /$ day, and $29.6 \%$ for mycophenolate mofetil (difference not statistically significant). At 12 months, creatinine clearance by Cockcroft-Gault was significantly lower in both everolimus arms $(52.9 \mathrm{cc} / \mathrm{min}$ and $49.3 \mathrm{cc} / \mathrm{min}$ for everolimus $1.5 \mathrm{mg} /$ day and $3 \mathrm{mg} /$ day, respectively) compared with mycophenolate mofetil $(56.9 \mathrm{cc} / \mathrm{min}$, $<0.05)$ despite similar biopsy-proven acute rejection between groups, resulting in the protocol amendment described above. As a result of the new protocol, creatinine clearance at 36 months was similar between the everolimus $1.5 \mathrm{mg} /$ day arm and mycophenolate mofetil and significantly lower 
in only the $3 \mathrm{mg} /$ day arm. ${ }^{65}$ Additional 3-year data show similar efficacy failure and biopsy-proven acute rejection rates between the everolimus $1.5 \mathrm{mg} /$ day, everolimus $3 \mathrm{mg} /$ day, and mycophenolate mofetil groups (33\% vs $38.9 \%$ vs $37.2 \%$, respectively, for efficacy failure, and $24.2 \%$ vs $24.7 \%$ vs $26.5 \%$, respectively, for biopsy-proven acute rejection, differences not statistically significant). ${ }^{65}$

The B251 study enrolled 583 patients and adopted a design identical to the B201, with the same protocol amendment described above. ${ }^{66}$ The primary endpoint of efficacy failure at 36 months, including biopsy-proven acute rejection, graft loss, death, or loss to follow-up, occurred in equal numbers across groups $(33.7 \%$ vs $34 \%$ vs $31.1 \%$ in the everolimus $1.5 \mathrm{mg} /$ day, everolimus $3 \mathrm{mg} / \mathrm{day}$, and mycophenolate mofetil groups, respectively, differences not statistically significant), as did biopsy-proven acute rejection at 36 months ( 25.4 vs 25.8 vs 26.5 , respectively). Interestingly, the incidence of antibody-mediated rejection was nearly double in the mycophenolate mofetil arm (18.4\%) compared with the everolimus $1.5 \mathrm{mg} /$ day arm (9.8\%). As in the B201 study, creatinine clearance was lower at 12 months in the two everolimus arms compared with mycophenolate mofetil (58 vs 52 vs $67 \mathrm{cc} / \mathrm{min}$ for everolimus $1.5 \mathrm{mg} /$ day, everolimus $3 \mathrm{mg} /$ day, and mycophenolate mofetil, respectively, Cockcroft-Gault, $P<0.01$ for either everolimus arm vs mycophenolate mofetil), and this trend held true at 36 months as well, despite the protocol amendment.

\section{Everolimus + reduced dose cyclosporine A}

While the studies B201 and B251 showed that fixed-dose everolimus in combination with full-dose cyclosporine A was effective and not inferior to a mycophenolate mofetil-based regimen in preventing biopsy-proven acute rejection and graft loss in kidney transplant recipients, lower creatinine clearance in the everolimus arms raised concerns about a potentiating effect on calcineurin inhibitor nephrotoxicity. While mTOR-I mediated potentiation of calcineurin inhibitor nephrotoxicity is well described, ${ }^{67}$ the differing mechanisms of action of these therapies have led to the hypothesis that they are also synergistic, ${ }^{15}$ possibly requiring a reduction in cyclosporine A exposure in combination with everolimus.

The 156 study was a 36-month, multicenter, randomized, open-label Phase II evaluation of the effectiveness of everolimus $3 \mathrm{mg} /$ day in combination with prednisone and either full-dose (trough goal 150-300 ng/mL at months $1-2,125-250 \mathrm{ng} / \mathrm{mL}$ at months $3-36$ ) or reduced-dose (trough goal 75-125 ng/mL at months $1-2,50-100 \mathrm{ng} / \mathrm{mL}$ at months 3-36) cyclosporine A with basiliximab induction in 111 kidney transplant recipients. ${ }^{68}$ As in the B201 and B251 studies, a protocol amendment allowing a reduction of trough cyclosporine A levels to $50-75 \mathrm{ng} / \mathrm{mL}$ was applied to all patients at 12 months, in addition to everolimus dose adjustments to maintain trough concentrations $>3 \mathrm{ng} / \mathrm{mL}$. Efficacy failure (biopsy-proven acute rejection, graft loss, death, loss to follow-up) at 36 months occurred in $35.8 \%$ of those on full-dose cyclosporine A vs $17.2 \%$ of those on reduced dose cyclosporine $\mathrm{A}(P=0.03)$. Creatinine clearance at 36 months (by Nankivell formula) was similar between groups $(51.7 \mathrm{cc} / \mathrm{min}$ for full-dose cyclosporine A vs $56.6 \mathrm{cc} /$ min for reduced-dose cyclosporine A), and improved from $49.7 \mathrm{cc} / \mathrm{min}$ preamendment to $54.5 \mathrm{cc} / \mathrm{min}$ at 6 months postamendment in the full-dose cyclosporine A group.

A retrospective analyses of the B201 and B251 studies revealed a significantly increased risk of biopsyproven acute rejection in patients with trough everolimus levels $<3 \mathrm{ng} / \mathrm{mL},{ }^{38,39}$ making the case for therapeutic monitoring of everolimus levels as a more optimal dosing strategy. With these data in mind, the A2306 and A2307 trials were undertaken to evaluate the effectiveness of concentrationcontrolled everolimus in combination with reduced dose cyclosporine A. ${ }^{69,70}$ These multicenter, randomized, openlabel studies of similar design evaluated the efficacy of two doses of everolimus ( $1.5 \mathrm{mg}$ /day or $3 \mathrm{mg}$ /day) plus low-dose cyclosporine A and prednisone. Patients in the A2306 study $(\mathrm{n}=237)$ received initial cyclosporine A doses of $8 \mathrm{mg} /$ $\mathrm{kg}$ /day and no induction therapy, while those in the A2307 study $(n=256)$ received induction therapy with basiliximab and lower initial doses of cyclosporine $\mathrm{A}$ at $4 \mathrm{mg} / \mathrm{kg} /$ day. Cyclosporine A exposure was monitored by 2-hour levels (C2) in both studies, with month 1 and 2 C2 goals in A2307 being approximately half those in the A2306 study. Nonblack patients in both studies received everolimus at either $1.5 \mathrm{mg} /$ day or $3 \mathrm{mg} /$ day, which was dose-adjusted to maintain trough concentrations $>3 \mathrm{ng} / \mathrm{mL}$, while all black patients received $3 \mathrm{mg} /$ day (based on higher everolimus clearance rates in black patients). ${ }^{31}$ Mean 6-month trough cyclosporine A levels ranged from $81.7 \mathrm{ng} / \mathrm{mL}$ to $83.1 \mathrm{ng} / \mathrm{mL}$ in $\mathrm{A} 2306$ and $63.7 \mathrm{ng} / \mathrm{mL}$ to $67.7 \mathrm{ng} / \mathrm{mL}$ in A2307. The primary endpoint of 6-month median glomerular filtration rate by Nankivell formula was similar across groups (65 vs $62 \mathrm{cc} / \mathrm{min}$ for everolimus $1.5 \mathrm{mg} /$ day and $3 \mathrm{mg} /$ day, respectively, in A2306, and $66 \mathrm{cc} / \mathrm{min}$ vs $67 \mathrm{cc} / \mathrm{min}$ for everolimus $1.5 \mathrm{mg} /$ day and $3 \mathrm{mg} /$ day, respectively, in A2307). The secondary endpoint of 6-month biopsy-proven acute rejection was reached by more patients on everolimus $1.5 \mathrm{mg}$ /day in A2306 (25\% vs $15.2 \%$ for everolimus $3 \mathrm{mg} /$ day), but was not statistically significant 
$(P=0.073)$, whereas biopsy-proven acute rejection was less frequent and equivalent between groups in the A2307 study with basiliximab induction ( $13.7 \%$ vs $15.1 \%$ for everolimus $1.5 \mathrm{mg} /$ day and $3 \mathrm{mg} /$ day, respectively, $P=0.859)$. Patients with trough everolimus concentrations $<3 \mathrm{ng} / \mathrm{mL}$ in either study had significantly more biopsy-proven acute rejection (6/8 vs 38/221 with everolimus $>3 \mathrm{ng} / \mathrm{mL}$ in $\mathrm{A} 2306$, $P<0.001$, and $3 / 6$ vs $31 / 246$ with everolimus $>3 \mathrm{ng} / \mathrm{mL}$ in A2307, $P<0.05$ ), consistent with the aforementioned retrospective analysis of biopsy-proven acute rejection risk and trough everolimus levels in the B201 and B256 studies. ${ }^{38,39}$

Twelve-month data from A2306 and A2307 show preserved glomerular filtration rates in both treatment groups (64 cc/min and $63 \mathrm{cc} / \mathrm{min}$ for everolimus $1.5 \mathrm{mg} /$ day and $3 \mathrm{mg} /$ day in A2306, respectively, and $68 \mathrm{cc} / \mathrm{min}$ for both groups in A2307) and similar trends in biopsy-proven acute rejection $(25.9 \%$ and $19.2 \%$ for everolimus $1.5 \mathrm{mg} /$ day and $3 \mathrm{mg} /$ day, respectively, in A2306; 13.7\% and 15.8\% for everolimus $1.5 \mathrm{mg}$ /day and $3 \mathrm{mg}$ /day, respectively, in A2307). ${ }^{70}$ Comparisons with data from the B201 and B251 trials of fixed-dose everolimus plus full-dose cyclosporine A show similar rates of biopsy-proven acute rejection, with significant improvements in 12-month renal function (in the range of $49-58 \mathrm{cc} / \mathrm{min}$ in $\mathrm{B} 201$ and $\mathrm{B} 256 \mathrm{vs} 63-65 \mathrm{cc} / \mathrm{min}$ in A2307 and 2307).

Taken together, data from the B201, B251, 156, A2306, and A2307 studies suggest a dosing strategy consisting of concentration-controlled everolimus with trough levels $>3 \mathrm{ng} / \mathrm{mL}$ in combination with low-dose cyclosporine A provides adequate immunosuppression while minimizing nephrotoxicity. The recently published A2309 study compared this optimized everolimus-based strategy with a more standard calcineurin inhibitor/mycophenolate mofetil-based regimen in 833 low-risk recipients of cadaveric or living donor kidneys. ${ }^{71}$ This multicenter, openlabel Phase III trial randomized patients to receive either everolimus $1.5 \mathrm{mg} /$ day (trough target $3-8 \mathrm{ng} / \mathrm{mL}$ ) with reduced dose cyclosporine $\mathrm{A}$, everolimus $3 \mathrm{mg} /$ day (trough target 6-12 ng/mL) with reduced-dose cyclosporine A, or mycophenolate mofetil $720 \mathrm{mg}$ twice daily with full-dose cyclosporine $\mathrm{A}$, in addition to basiliximab induction and maintenance prednisone. Target cyclosporine A trough levels in both everolimus arms were $100-200 \mathrm{ng} / \mathrm{mL}$ in months $1-2$ and were tapered to $25-50 \mathrm{ng} / \mathrm{mL}$ by month 12 , compared with $200-300 \mathrm{ng} / \mathrm{mL}$ in months $1-2$ and $100-250 \mathrm{ng} / \mathrm{mL}$ thereafter for patients in the mycophenolate mofetil arm. The primary composite endpoint of 1-year biopsy-proven acute rejection, graft loss, death, or loss to follow-up occurred in similar numbers in each treatment arm $(25.3 \%, 21.9 \%$, and $24.2 \%$ in the everolimus $1.5 \mathrm{mg} /$ day, everolimus $3 \mathrm{mg} /$ day, and mycophenolate mofetil groups, respectively). Biopsyproven acute rejection itself occurred in similar numbers as well $(16.2 \%, 13.3 \%$, and $17 \%$ in the everolimus $1.5 \mathrm{mg} / \mathrm{day}$, everolimus $3 \mathrm{mg} / \mathrm{day}$, and mycophenolate mofetil groups, respectively) and consisted mainly of mild Banff Grade IA episodes in all groups. One-year glomerular filtration rate by Nankivell formula was also equivalent between the groups (65.8 cc/min, $64 \mathrm{cc} / \mathrm{min}$, and $62.6 \mathrm{cc} / \mathrm{min}$ for everolimus $1.5 \mathrm{mg} /$ day, everolimus $3 \mathrm{mg} / \mathrm{day}$, and mycophenolate mofetil groups, respectively).

The A2309 study thus confirms that the efficacy of a concentration-controlled everolimus-based protocol is equivalent to a mycophenolic acid-based regimen, while allowing for an average $60 \%$ reduction in calcineurin inhibitor exposure over a 12-month period. However, this study did not include a reduced-dose cyclosporine $\mathrm{A}+$ mycophenolate mofetil arm such as that seen in the 1645-patient Efficacy Limiting Toxicity Elimination (ELITE)-Symphony study (low-dose cyclosporine A, trough goal 50-100 ng/mL throughout the study) which was associated with comparable 12-month renal function (creatinine clearance $59.4 \mathrm{cc} / \mathrm{min}$ by CockcroftGault). ${ }^{11}$ Nevertheless, despite a similar 12-month glomerular filtration rate between the groups in the A2309 study, a 60\% reduction in calcineurin inhibitor exposure is an attractive treatment option for kidney transplant recipients that may result in improved longer-term graft function.

A more aggressive calcineurin inhibitor minimization strategy was employed in the recently published ZEUS trial in which 503 kidney transplant recipients receiving de novo cyclosporine A, mycophenolic acid, and prednisone were randomized 1:1 at post-transplant month 4-5 to either remain on cyclosporine A-based therapy (goal trough concentrations 120-180 ng/mL at month 4.5-6.0, and 100-150 ng/mL after month 6) or undergo cyclosporine A conversion to everolimus (goal trough concentration 3-8 ng/mL during conversion and $6-10 \mathrm{ng} / \mathrm{mL}$ thereafter). ${ }^{72}$ At the time of conversion, 300 of the original 503 recipients met the criteria to proceed with conversion. The primary endpoint of glomerular filtration rate by Nankivell formula at 12 months post-transplant was significantly higher in the everolimus conversion group compared with patients remaining on a cyclosporine A-based regimen ( $71.8 \mathrm{cc} / \mathrm{min}$ vs $61.9 \mathrm{cc} / \mathrm{min}$, respectively). Biopsyproven acute rejection was significantly more common in everolimus-converted patients as well (10\% vs 3\% after randomization for nonconverted patients, $P=0.03$ ), but all rejections were categorized as mild. Nevertheless, late 
rejection episodes have been associated with poor graft outcomes in several studies, ${ }^{73,74}$ and further clinical studies are needed prior to recommending this strategy in clinical practice.

\section{Everolimus + tacrolimus}

While several trials have evaluated the use of sirolimus in combination with tacrolimus with varying results, ${ }^{75-77}$ a large retrospective analysis of Scientific Registry of Transplant Recipients data has shown this combination to be inferior to mycophenolate mofetil-based regimens. ${ }^{78}$ However, it is likely that these findings reflect increased nephrotoxicity as a result of higher tacrolimus trough levels, while lower tacrolimus exposure characteristic of recent practice may be associated with improved outcomes when combined with sirolimus. ${ }^{79}$ The US09 study was a 6-month multicenter, open-label, prospective randomized trial evaluating the use of everolimus with either standard-exposure or low-exposure tacrolimus. ${ }^{46}$ Low-risk kidney transplant recipients received basiliximab induction with maintenance steroids, everolimus at $1.5 \mathrm{mg}$ /day adjusted for trough values $>3 \mathrm{ng} / \mathrm{mL}$, and randomized to either low tacrolimus (trough 4-7 ng/mL in months $0-3$, and 3-6 $\mathrm{ng} / \mathrm{mL}$ in months $4-6$ ) or standard tacrolimus (trough $8-11 \mathrm{ng} / \mathrm{mL}$ in months $0-3$, and $7-10 \mathrm{ng} / \mathrm{mL}$ in months $4-6)$. Due to slow recruitment, the original goal of 202 patients was not reached, and enrollment stopped after 92 patients were included. The primary outcome of serum creatinine at 6 months needed to differ by at least $0.04 \mathrm{mg} / \mathrm{dL}$ in order to retain $80 \%$ power with a significance level of $P<0.05$.

The majority $(66 \%)$ of patients in this study received kidneys from living donors. Tacrolimus levels trended toward the upper end of the trough range for the low tacrolimus group and toward the lower end of the range for the standard tacrolimus group, resulting in less separation between groups than planned. Trough everolimus levels were equivalent in each group ( $5.2 \mathrm{ng} / \mathrm{mL}$ at 6 months). Six-month serum creatinine was lower in the low tacrolimus group (1.26 mg/dL vs $1.44 \mathrm{mg} / \mathrm{dL}$ for standard tacrolimus) but did not reach statistical significance $(P=0.114)$. Glomerular filtration rate by Nankivell formula was well preserved in each group at $75.3 \mathrm{cc} / \mathrm{min}$ for the low tacrolimus arm and $72.5 \mathrm{cc} / \mathrm{min}$ for the standard tacrolimus arm. Biopsy-proven acute rejection occurred in $14 \%$ of each group and most episodes were either Banff Grade IA or IB.

Everolimus in combination with either low-exposure or standard-exposure tacrolimus thus appears to maintain efficacy comparable with everolimus/cyclosporine A-based regimens at 6 months, but a longer follow-up period may reveal significant differences in renal function between groups. This, in addition to poor recruitment, low number of deceased donors, and limited differentiation between tacrolimus arms, limits the applicability of this study, and results need to be interpreted with caution.

A post hoc analysis of data from the US09 study showed significantly fewer rejection episodes in patients with trough everolimus levels $>3 \mathrm{ng} / \mathrm{mL}^{45}$ similar to results seen in comparable retrospective analyses of everolimus plus fulldose cyclosporine A studies B201 and B251. ${ }^{64,66}$ As a result of these analyses, therapeutic monitoring of trough everolimus levels is recommended to maintain concentrations at 3-8 $\mathrm{ng} / \mathrm{mL}$.

\section{Safety, tolerability, and side effects}

mTOR-Is are associated with numerous potential side effects, which account for significant discontinuation rates in many sirolimus trials. Overall, the most common side effects associated with sirolimus in clinical trials have been lipid abnormalities, edema, lymphocele, delayed graft function, delayed wound healing, proteinuria, and hematologic abnormalities. ${ }^{80}$ While data regarding common side effects associated with everolimus are sparse due to the relatively recent introduction of this drug into clinical use, one can speculate a similar profile to sirolimus given their identical mechanisms of action. The following sections summarize the tolerability and adverse events reported from three large comparative trials described above.

\section{Safety and tolerability}

Studies comparing everolimus-based and mycophenolate mofetil-based regimens have generally shown similar patient survival but higher rates of drug discontinuation in the everolimus groups. In the B201 study, ${ }^{64,65}$ rates of death at 3 years were similar between both everolimus dose groups and mycophenolate mofetil, with the primary causes of death being myocardial infarction, sepsis, and pneumonia. The frequency of discontinuation of study medication due to adverse events was significantly higher in the higher-dose (everolimus $3 \mathrm{mg} /$ day) group compared with the mycophenolate mofetil group (39\% vs $28 \%$, respectively, $P=0.03$ ), while the lower-dose (everolimus $1.5 \mathrm{mg} /$ day) group was not different from the mycophenolate mofetil group (31\% vs $28 \%, P=0.57)$. Mortality in the B251 study was similar across groups, but a significantly higher rate of study drug discontinuation for any reason was observed in both everolimus groups compared with mycophenolate mofetil 
( $57 \%, 65 \%$, and $45 \%$ for everolimus $1.5 \mathrm{mg} / \mathrm{day}, 3 \mathrm{mg} / \mathrm{day}$, and mycophenolate mofetil groups, respectively), ${ }^{66}$ with the most common reason for drug discontinuation being adverse events. In the A2309 study, which included concentrationcontrolled everolimus dosing, study drug discontinuation due to adverse events was lower than reported in B201, but still higher in both everolimus groups compared with mycophenolate mofetil (23\% and 28\% vs 16\% for everolimus $1.5 \mathrm{mg} /$ day and $3 \mathrm{mg} /$ day vs mycophenolate mofetil, respectively, statistical significance not provided).$^{71}$ While the total number of patients discontinuing the study drug or requiring dose adjustment due to adverse events was less in those receiving $1.5 \mathrm{mg}$ /day compared with $3 \mathrm{mg} /$ day everolimus, a post hoc analysis did not reveal a significant relationship between the trough everolimus level and rate of discontinuation. ${ }^{71}$ Patient survival was similar in the everolimus and mycophenolate mofetil groups.

\section{Hyperlipidemia}

Hyperlipidemia is the most commonly reported side effect associated with mTOR-I use. A review of 17 randomized controlled trials comparing sirolimus-based or everolimusbased drug regimens with regimens without mTOR-Is identified higher cholesterol and triglycerides in patients receiving mTOR-Is in all but one trial, ${ }^{81}$ with two-fold higher use of lipid-lowering agents in these patients (60\%) compared with controls. This trend was seen in the B201 study, where mean total cholesterol and triglyceride levels were significantly higher for patients in both the everolimus $1.5 \mathrm{mg} /$ day and $3 \mathrm{mg}$ /day groups vs mycophenolate mofetil, ${ }^{65}$ as well as in the A2309 study, where high total cholesterol and hypertriglyceridemia were reported as adverse events more frequently in the everolimus groups than with mycophenolate mofetil. ${ }^{71}$ Hyperlipidemia was also reported more frequently for the everolimus groups compared with mycophenolate mofetil in the B251 study (27.5\% and 30.4\% for everolimus $1.5 \mathrm{mg} /$ day and $3 \mathrm{mg} /$ day, respectively, vs $22.4 \%$ for mycophenolate mofetil), although not statistically significant. ${ }^{66}$ In the A2307 study of concentration-controlled everolimus plus reduced-dose cyclosporine A, hyperlipidemia was reported as an adverse event in $37.6 \%$ and $33.1 \%$ of patients receiving $1.5 \mathrm{mg}$ /day and $3 \mathrm{mg} /$ day, respectively. ${ }^{70}$

\section{Anemia}

Anemia has frequently been associated with mTOR-I use. A study of 214 de novo kidney transplant recipients treated with either sirolimus-based or mycophenolate mofetil-based therapy showed significantly more anemia with sirolimus
(57\%) than with mycophenolate mofetil $(31 \%, P<0.001) .{ }^{82}$ Additionally, conversion from sirolimus to mycophenolate mofetil appeared to result in increased hemoglobin levels in stable kidney transplant recipients. ${ }^{83}$ The mechanism responsible for mTOR-I-induced anemia is unclear; hypotheses include a direct effect on iron homeostasis ${ }^{84}$ and induction of a chronic inflammatory state. ${ }^{85}$ In the latter study, 48 patients on calcineurin inhibitor-based therapy were converted to an everolimus-based regimen, with anemia increasing from $18.6 \%$ preconversion to $35 \%$ at 3 months after conversion. This everolimus-associated anemia was characterized by microcytosis, low serum iron, high serum ferritin, and elevated C-reactive protein. Interestingly, at 6 months after conversion, the percentage of anemic patients had returned to 18.6 despite no differences in the use of darbopoeitin, suggesting an initial period of inflammation and anemia that normalized with time. ${ }^{85}$ Despite this observation, at 36 months, significantly more anemia-related adverse events were reported for everolimus $1.5 \mathrm{mg} /$ day and $3 \mathrm{mg} /$ day compared with mycophenolate mofetil (32.1\% and 39.2\% vs $21.4 \%$, respectively) in the B251 study. ${ }^{66}$

\section{Proteinuria}

Sirolimus use has been frequently associated with proteinuria. ${ }^{86}$ This finding appears to occur mainly in patients converted from calcineurin inhibitors to sirolimus, ${ }^{87,88}$ but has also been reported with de novo sirolimus use as well. ${ }^{89,90}$ While the mechanism of proteinuria in the former scenario is likely to involve hemodynamic glomerular changes after calcineurin inhibitor removal, the mechanism associated with de novo sirolimus use is unclear. Proposed mechanisms include a loss of tubular reabsorption of protein ${ }^{89}$ and an inhibitory action of sirolimus on vascular endothelial growth factor. ${ }^{86}$ Recently, de novo mTOR-I use was shown to be associated with a loss of nephrin in glomeruli, ${ }^{91}$ offering yet another possible mechanism for this phenomenon. In the B251 study, where all groups received a calcineurin inhibitor, proteinuria $>300 \mathrm{mg} /$ day was more frequent in both everolimus arms compared with mycophenolate mofetil $(39.5 \%$ and $39.2 \%$ on everolimus $1.5 \mathrm{mg} /$ day and $3 \mathrm{mg} /$ day vs $14.9 \%$ in mycophenolate mofetil, $P<0.0001)$, as was more severe proteinuria $>1 \mathrm{~g} /$ day $(11.6 \%$ and $11.4 \%$ in everolimus $1.5 \mathrm{mg} /$ day and $3 \mathrm{mg} /$ day vs $2.3 \%$ in mycophenolate mofetil, $P=0.028$ ), suggesting a direct relationship between everolimus and proteinuria. ${ }^{66}$

\section{Peritransplant complications}

Reporting of delayed graft function in clinical trials is subject to considerable variability due to differences in 
kidney donor characteristics, ischemia time, delayed graft function definition, and other aspects of the study design. Nevertheless, delayed graft function has been frequently associated with sirolimus use, ${ }^{92-94}$ and a retrospective study of 8319 recipients of kidneys from deceased donors, 361 of whom had received de novo sirolimus, revealed an increased risk of delayed graft function in sirolimus-treated patients, with an odds ratio of 1.42 (95\% confidence interval: 1.07-1.9). ${ }^{95}$ Contrary to these data, however, are data from the ELITE-Symphony study in which patients in the de novo sirolimus arm experienced significantly less delayed graft function (defined by persistent oliguria, decrease in serum creatinine $\leq 0.5 \mathrm{mg} / \mathrm{dL}$ within 24 hours posttransplant, or dialysis) compared with both the cyclosporine A and tacrolimus arms. ${ }^{11}$ In studies of everolimus and a non-everolimus-treated comparator group, the incidence of delayed graft function was similar between everolimus and mycophenolate mofetil groups. ${ }^{64-66,71}$ In these studies, the incidence of delayed graft function in everolimus-treated patients ranged from $7.8 \%$ in the B251 study, which included $50 \%$ deceased donor kidneys and excluded those with delayed graft function within the first 48 hours, to $32 \%$ in the B201 study, which included $90 \%$ deceased donor kidneys without specific delayed graft function-related exclusion criteria. The US09 study of everolimus in combination with tacrolimus also reported low delayed graft function rates of $8.2 \%-9.3 \%$, although the study design included an option for withholding everolimus in the case of delayed graft function. ${ }^{46}$ Thus, while the data for sirolimus are mixed, initial experience does not implicate everolimus as a significant risk factor for delayed graft function. In accordance with these data, a study of 139 patients receiving kidneys at high risk for delayed graft function (donor age $>55$ years, cold ischemia time $>24$ hours, or retransplantation) randomized to receive everolimus either de novo or as replacement for mycophenolate mofetil at 5 months post-transplant, in addition to cyclosporine A and prednisone, showed similar delayed graft function rates in both groups $(24.6 \%$ immediate everolimus, $24.3 \%$ delayed everolimus). ${ }^{96}$

The association of mTOR-Is with lymphocele development and impaired wound healing is less controversial and now well documented. ${ }^{97-100}$ Clinical trials of everolimus show lymphocele development ranging from $4 \%$ in the US09 study ${ }^{46}$ to $18 \%$ in the B251 study. ${ }^{66}$ In B201, lymphocele was significantly more likely to occur in either everolimus group compared with mycophenolate mofetil ( $9 \%$ and $12 \% \mathrm{vs} 4 \%$ for everolimus $1.5 \mathrm{mg} /$ day and $3 \mathrm{mg} /$ day vs mycophenolate mofetil, respectively). ${ }^{64,65}$ Obese patients are particularly susceptible to wound complications, and in the A2309 study, wound healing events in patients with body mass index $>75$ th percentile were reported in $50 \%$ of the everolimus group vs $27 \%$ of the mycophenolate mofetil group $(P<0.05) .^{70}$

\section{Infection}

While suppression of the recipient immune system allows for successful organ transplantation with increasingly minimal risk of rejection episodes, infectious complications are an unfortunate and frequent consequence. In the A2306 and 2307 studies of concentration-controlled everolimus plus low-dose cyclosporine A, infections were reported in $62 \%-64 \%$ of patients across groups, with serious infections reported in $14 \%-17 \%$ of all patients. ${ }^{69,70}$ In the B201, B251, and A2309 studies comparing various everolimus doses with mycophenolate mofetil-treated patients, overall rates of reported infections were similar across groups, at approximately $60 \%-70 \%{ }^{65,66,71}$ Whereas reported bacterial infections were similar between groups in these studies, a closer look at specific viral infections reveals some important differences. In the B201 study, viral infection was significantly more likely to occur in mycophenolate mofetil-treated patients compared with everolimus-treated patients $(29.1 \%$ for mycophenolate mofetil vs $13.4 \%$ and $12.6 \%$ for everolimus $1.5 \mathrm{mg}$ /day and $3 \mathrm{mg} /$ day, $P<0.025$ ). Cytomegalovirus infection in particular was significantly less likely in both everolimus groups $(5.7 \%$ and $8.1 \%$ for everolimus $1.5 \mathrm{mg} /$ day and $3 \mathrm{mg}$ /day vs $19.9 \%$ for mycophenolate mofetil, $P=0.001)$. The A2309 study also reported higher cytomegalovirus infection rates in mycophenolate mofetil-treated patients compared with everolimus-treated patients $(5.9 \%$ vs $0.7 \%$ and $0 \%$ for everolimus $1.5 \mathrm{mg} /$ day and $3 \mathrm{mg}$ /day), as well as higher BK viruria and viremia rates $(3.3 \%$ and $1.8 \%$, respectively, vs $0.7 \%$ and $1.1 \%$ for everolimus $1.5 \mathrm{mg} /$ day and $0.4 \%$ and $0.7 \%$ for everolimus $3 \mathrm{mg} /$ day). Rates of cytomegalovirus infection were similar in mycophenolate mofetil-treated and everolimus-treated patients in the B251 study. Therefore, everolimus-based regimens appear to result in similar overall infection rates compared with mycophenolate mofetil, but may offer an advantage with regard to viral disease.

\section{Malignancy}

The risk of malignancy associated with organ transplantation and immunosuppression is considerably higher than that in the general population for almost all types of cancer, ${ }^{101-103}$ with differences ranging from a two-fold increased risk 
of solid tumors of the colon, lung, prostate, and breast, to a 20-fold increased risk of nonmelanoma skin cancer and non-Hodgkin's lymphoma. ${ }^{104}$ Given the antiproliferative effect that results from blockade of the mTOR signaling pathway, one might expect a more favorable malignancy profile associated with chronic mTOR-I use compared with other immunosuppressive agents. Indeed, the proliferation pathway downregulated by mTOR inhibition contains several enzymes that are important in tumor growth and development. ${ }^{105}$ Clinically, 5-year follow-up of the Rapamune ${ }^{\circledR}$ Maintenance Regimen study showed reduced incidence of both skin and nonskin malignancy in sirolimus-treated patients who underwent cyclosporine A withdrawal at 3 months posttransplant compared with patients on both sirolimus and cyclosporine A, ${ }^{106}$ and the CONVERT study showed significantly lower rates of malignancy at 2 years in patients converted from a calcineurin inhibitor to sirolimus compared with those who remained on a calcineurin inhibitor alone. ${ }^{10}$

The antiproliferative properties of everolimus have led to its therapeutic use in several malignancies, including advanced renal cell carcinoma and subependymal giant cell astrocytoma. ${ }^{107,108}$ However, conclusions regarding malignancy resulting from chronic everolimus therapy in kidney transplant recipients are limited due to its recent introduction into clinical practice and a lack of sufficient long-term follow-up data. Three-year results of the B251 and B201 studies show low rates of malignancy that are equivalent across everolimus and mycophenolate mofetil groups, in the range of $4.5 \%-6.1 \%{ }^{65,66}$ Of interest, eight cases of posttransplant lymphoproliferative disorder were reported in both B201 and B251, all of which occurred in patients receiving everolimus (six cases in the everolimus $1.5 \mathrm{mg} /$ day group, and two in the everolimus $3 \mathrm{mg}$ /day group). Because the phospho-inositide 3-kinase/Akt/mTOR signaling pathway plays an important role in post-transplant lymphoproliferative disorder-associated Epstein-Barr-positive lymphoma, ${ }^{109}$ an association between everolimus and post-transplant lymphoproliferative disorder would be unexpected, but nevertheless deserves close attention, given these data.

\section{Other mTOR-I related adverse events}

Pneumonitis and hemolytic uremic syndrome are rare but potentially serious syndromes that have been associated with sirolimus use, ${ }^{110-114}$ the latter reported in patients treated with sirolimus/cyclosporine A combinations. In the case of pneumonitis, withdrawal of sirolimus commonly results in full recovery. Everolimus-associated pneumonitis has been reported in three heart transplant recipients, ${ }^{115}$ but has not been described in clinical trials of everolimus use in kidney transplantation. Hemolytic uremic syndrome, on the other hand, was reported in a total of nine patients receiving everolimus with full-dose cyclosporine A in the B201 and B251 studies, compared with one patient receiving mycophenolate mofetil. ${ }^{65,66}$ Hemolytic Uremic syndrome was not reported in the A2306, A2307, and A2309 studies of everolimus plus reduced-dose cyclosporine A or in the US09 study of everolimus plus tacrolimus, suggesting that minimizing combined sirolimus and cyclosporine A exposure reduces the risk of this disease. ${ }^{46,70,71}$

Several other less serious, albeit troubling from the patient's prospective, cutaneous side effects have been attributed specifically to chronic mTOR-I use, including edema, acne, and apthous mouth ulceration. ${ }^{16,117}$ Edema was one of three adverse events (along with diarrhea and lymphocele) reported as significantly more common for everolimus-treated patients compared with mycophenolate mofetil-treated patients in the B201 study (22.2\% and $18.7 \%$ for everolimus $1.5 \mathrm{mg} /$ day and $3 \mathrm{mg} /$ day vs $13.3 \%$ for mycophenolate mofetil), ${ }^{65}$ and one of two adverse events (along with anemia) more common in everolimus vs mycophenolate mofetil-treated patients in B251 (52.3\% and 47.4\% for everolimus $1.5 \mathrm{mg} /$ day and $3 \mathrm{mg} /$ day vs $41.8 \%$ for mycophenolate mofetil). ${ }^{66}$ Acne was reported in approximately $20 \%$ of each group in the B251 study, and mouth ulcers were reported in $0.5 \%-5 \%$ of everolimus-treated patients in B251 and A2309 vs 1.5\%-1.8\% of mycophenolate mofetil-treated patients. ${ }^{66,71}$

\section{Everolimus and FDA-mandated education and monitoring for patients and providers}

Based upon the side effect profile above and the adverse event reporting data from the 2309 trial and earlier studies, everolimus gained approval in the US for kidney transplantation, with the expectation that health care professionals and patients be informed and monitored for certain side effects, referred to as a Risk Evaluation and Mitigation Strategy (REMS). This communication plan includes a health care professional and professional association letter to transplant surgeons, transplant medical physicians, physician extenders, and pharmacists, describing the increased risks of woundrelated events, hyperlipidemia, proteinuria, graft thrombosis, and nephrotoxicity when coadministered with standarddose cyclosporine $\mathrm{A}$, as well as a medication guide for patients enclosed in all everolimus packaging that describes 
these risks. Periodic surveys of patients and providers will be performed by Novartis, the manufacturer of everolimus, to ensure that the REMS is adequately conveying the need for increased attention to these potential complications.

\section{Conclusion}

Clinical trials have demonstrated that the mTOR-I, everolimus, in combination with reduced-dose cyclosporine A or tacrolimus, is effective in preventing rejection episodes and graft loss while preserving adequate renal function, resulting in its recent Food and Drug Administration approval for use in combination with reduced-dose cyclosporine A, corticosteroids, and basiliximab in kidney transplant recipients at low to moderate immunologic risk. Compared with mycophenolate mofetil-based regimens, everolimus allows for a significant reduction in cyclosporine A exposure, which may translate into improved longer-term graft outcomes. Rates of viral infections and malignancy may be favorably impacted by the use of everolimus and is deserving of further study. These potential advantages must be weighed against the side effect profile of everolimus when selecting an optimal immunosuppressive regimen for kidney transplant recipients.

\section{Disclosure}

ACW has served as a consultant to Novartis, and UC has received grant support from Novartis. JEC has no conflicts of interest to report in this work.

\section{References}

1. Laupacis A, Keown P, Pus N, et al. A study of the quality of life and cost-utility of renal transplantation. Kidney Int. 1996;50(1):235-242.

2. Wolfe RA, Ashby VB, Milford EL, et al. Comparison of mortality in all patients on dialysis, patients on dialysis awaiting transplantation, and recipients of a first cadaveric transplant. $N$ Engl J Med. 1999;341(23): $1725-1730$.

3. Chan L, Gaston R, Hariharan S. Evolution of immunosuppression and continued importance of acute rejection in renal transplantation. Am J Kidney Dis. 2001;38(6 Suppl 6):S2-S9.

4. 2009 Annual Report of the US Organ Procurement and Transplantation Network and the Scientific Registry of Transplant Recipients: Transplant Data 1999-2008. Rockville, MD: US Department of Health and Human Services, Health Resources and Services Administration, Healthcare Systems Bureau, Division of Transplantation; 2009.

5. Pascual M, Theruvath T, Kawai T, Tolkoff-Rubin N, Cosimi AB. Strategies to improve long-term outcomes after renal transplantation. N Engl J Med. 2002;346(8):580-590.

6. Lamb KE, Lodhi S, Meier-Kriesche HU. Long-term renal allograft survival in the United States: A critical reappraisal. Am J Transplant. 2011;11(3):450-462.

7. Meier-Kriesche HU, Schold JD, Srinivas TR, Kaplan B. Lack of improvement in renal allograft survival despite a marked decrease in acute rejection rates over the most recent era. Am J Transplant. 2004;4(3): $378-383$.
8. Oberbauer R, Segoloni G, Campistol JM, et al. Early cyclosporine withdrawal from a sirolimus-based regimen results in better renal allograft survival and renal function at 48 months after transplantation. Transpl Int. 2005;18(1):22-28.

9. Lebranchu Y, Thierry A, Toupance O, et al. Efficacy on renal function of early conversion from cyclosporine to sirolimus 3 months after renal transplantation: Concept study. Am J Transplant. 2009;9(5): $1115-1123$.

10. Schena FP, Pascoe MD, Alberu J, et al. Conversion from calcineurin inhibitors to sirolimus maintenance therapy in renal allograft recipients: 24-month efficacy and safety results from the CONVERT trial. Transplantation. 2009;87(2):233-242.

11. Ekberg H, Tedesco-Silva H, Demirbas A, et al. Reduced exposure to calcineurin inhibitors in renal transplantation. $N$ Engl $J$ Med. 2007;357(25):2562-2575.

12. Schuler W, Sedrani R, Cottens S, et al. SDZ RAD, a new rapamycin derivative: Pharmacological properties in vitro and in vivo. Transplantation. 1997;64(1):36-42.

13. Crowe A, Bruelisauer A, Duerr L, Guntz P, Lemaire M. Absorption and intestinal metabolism of SDZ-RAD and rapamycin in rats. Drug Metab Dispos. 1999;27(5):627-632.

14. Kahan BD, Kaplan B, Lorber MI, Winkler M, Cambon N, Boger RS. RAD in de novo renal transplantation: Comparison of three doses on the incidence and severity of acute rejection. Transplantation. 2001; 71(10):1400-1406.

15. Schuurman HJ, Cottens S, Fuchs S, et al. SDZ RAD, a new rapamycin derivative: Synergism with cyclosporine. Transplantation. 1997;64(1): 32-35.

16. Zoncu R, Efeyan A, Sabatini DM. mTOR: From growth signal integration to cancer, diabetes and ageing. Nat Rev Mol Cell Biol. 2011;12(1): 21-35.

17. Terada N, Lucas JJ, Szepesi A, Franklin RA, Takase K, Gelfand EW. Rapamycin inhibits the phosphorylation of p70 S6 kinase in IL-2 and mitogen-activated human T cells. Biochem Biophys Res Commun. 1992;186(3):1315-1321.

18. Kuo CJ, Chung J, Fiorentino DF, Flanagan WM, Blenis J, Crabtree GR. Rapamycin selectively inhibits interleukin-2 activation of p70 S6 kinase. Nature. 1992;358(6381):70-73.

19. Sedrani R, Cottens S, Kallen J, Schuler W. Chemical modification of rapamycin: The discovery of SDZ RAD. Transplant Proc. 1998; 30(5):2192-2194.

20. Dumont FJ. Everolimus. Novartis. Curr Opin Investig Drugs. 2001; 2(9):1220-1234.

21. Crowe A, Lemaire M. In vitro and in situ absorption of SDZ-RAD using a human intestinal cell line (Caco-2) and a single pass perfusion model in rats: Comparison with rapamycin. Pharm Res. 1998;15(11): 1666-1672.

22. Kirchner GI, Meier-Wiedenbach I, Manns MP. Clinical pharmacokinetics of everolimus. Clin Pharmacokinet. 2004;43(2):83-95.

23. Kovarik JM, Hartmann S, Figueiredo J, Rouilly M, Port A, Rordorf C. Effect of rifampin on apparent clearance of everolimus. Ann Pharmacother. 2002;36(6):981-985.

24. Kovarik JM, Kahan BD, Kaplan B, et al. Longitudinal assessment of everolimus in de novo renal transplant recipients over the first posttransplant year: Pharmacokinetics, exposure-response relationships, and influence on cyclosporine. Clin Pharmacol Ther. 2001;69(1): $48-56$.

25. Jacobsen W, Serkova N, Hausen B, Morris RE, Benet LZ, Christians U. Comparison of the in vitro metabolism of the macrolide immunosuppressants sirolimus and RAD. Transplant Proc. 2001;33(1-2):514-515.

26. Filler G, Bendrick-Peart J, Christians U. Pharmacokinetics of mycophenolate mofetil and sirolimus in children. Ther Drug Monit. 2008;30(2):138-142.

27. Filler G, Bendrick-Peart J, Strom T, Zhang YL, Johnson G, Christians U. Characterization of sirolimus metabolites in pediatric solid organ transplant recipients. Pediatr Transplant. 2009;13(1):44-53. 
28. Zollinger M, Sayer C, Dannecker R, Schuler W, Sedrani R. The macrolide everolimus forms an unusual metabolite in animals and humans: Identification of a phosphocholine ester. Drug Metab Dispos. 2008;36(8):1457-1460.

29. Christians U, Sattler M, Schiebel HM, et al. Isolation of two immunosuppressive metabolites after in vitro metabolism of rapamycin. Drug Metab Dispos. 1992;20(2):186-191.

30. Kuhn B, Jacobsen W, Christians U, Benet LZ, Kollman PA. Metabolism of sirolimus and its derivative everolimus by cytochrome P450 3A4: Insights from docking, molecular dynamics, and quantum chemical calculations. J Med Chem. 2001;44(12):2027-2034.

31. Kovarik JM, Hsu CH, McMahon L, Berthier S, Rordorf C. Population pharmacokinetics of everolimus in de novo renal transplant patients: Impact of ethnicity and comedications. Clin Pharmacol Ther. 2001; 70(3):247-254.

32. Christians U, Schmitz V, Haschke M. Functional interactions between P-glycoprotein and CYP3A in drug metabolism. Expert Opin Drug Metab Toxicol. 2005;1(4):641-654.

33. Everolimus prescribing information. Available at: http://www.pharma. us.novartis.com/product/pi/pdf/zortress.pdf. 2010. Accessed on March 31, 2011.

34. Kovarik JM, Sabia HD, Figueiredo J, et al. Influence of hepatic impairment on everolimus pharmacokinetics: Implications for dose adjustment. Clin Pharmacol Ther. 2001;70(5):425-430.

35. Benet LZ. Relevance of pharmacokinetics in narrow therapeutic index drugs. Transplant Proc. 1999;31(3):1642-1644.

36. Anglicheau D, Legendre C, Beaune P, Thervet E. Cytochrome P450 3 A polymorphisms and immunosuppressive drugs: An update. Pharmacogenomics. 2007;8(7):835-849.

37. Kovarik JM, Kaplan B, Silva HT, et al. Pharmacokinetics of an everolimus-cyclosporine immunosuppressive regimen over the first 6 months after kidney transplantation. Am J Transplant. 2003;3(5):606-613.

38. Kovarik JM, Kaplan B, Tedesco Silva H, et al. Exposure-response relationships for everolimus in de novo kidney transplantation: Defining a therapeutic range. Transplantation. 2002;73(6):920-925.

39. Lorber MI, Ponticelli C, Whelchel J, et al. Therapeutic drug monitoring for everolimus in kidney transplantation using 12-month exposure, efficacy, and safety data. Clin Transplant. 2005;19(2):145-152.

40. Kaplan B, Meier-Kriesche HU, Napoli KL, Kahan BD. The effects of relative timing of sirolimus and cyclosporine microemulsion formulation coadministration on the pharmacokinetics of each agent. Clin Pharmacol Ther. 1998;63(1):48-53.

41. Kovarik JM, Kalbag J, Figueiredo J, Rouilly M, Frazier OL, Rordorf C. Differential influence of two cyclosporine formulations on everolimus pharmacokinetics: A clinically relevant pharmacokinetic interaction. J Clin Pharmacol. 2002;42(1):95-99.

42. Budde K, Lehne G, Winkler M, et al. Influence of everolimus on steadystate pharmacokinetics of cyclosporine in maintenance renal transplant patients. J Clin Pharmacol. 2005;45(7):781-791.

43. McAlister VC, Mahalati K, Peltekian KM, Fraser A, MacDonald AS. A clinical pharmacokinetic study of tacrolimus and sirolimus combination immunosuppression comparing simultaneous to separated administration. Ther Drug Monit. 2002;24(3):346-350.

44. Kovarik JM, Curtis JJ, Hricik DE, Pescovitz MD, Scantlebury V, Vasquez A. Differential pharmacokinetic interaction of tacrolimus and cyclosporine on everolimus. Transplant Proc. 2006;38(10):3456-3458.

45. Chan L, Hartmann E, Cibrik D, Cooper M, Shaw LM. Optimal everolimus concentration is associated with risk reduction for acute rejection in de novo renal transplant recipients. Transplantation. 2010;90(1):31-37.

46. Chan L, Greenstein S, Hardy MA, et al. Multicenter, randomized study of the use of everolimus with tacrolimus after renal transplantation demonstrates its effectiveness. Transplantation. 2008;85(6):821-826.

47. Kovarik JM, Hartmann S, Figueiredo J, et al. Effect of food on everolimus absorption: Quantification in healthy subjects and a confirmatory screening in patients with renal transplants. Pharmacotherapy. 2002;22(2):154-159.
48. Lown KS, Bailey DG, Fontana RJ, et al. Grapefruit juice increases felodipine oral availability in humans by decreasing intestinal CYP3A protein expression. J Clin Invest. 1997;99(10):2545-2553.

49. Mannel M. Drug interactions with St John's wort: Mechanisms and clinical implications. Drug Saf. 2004;27(11):773-797.

50. Morgan ET. Regulation of cytochromes $\mathrm{P} 450$ during inflammation and infection. Drug Metab Rev. 1997;29(4):1129-1188.

51. Iber H, Sewer MB, Barclay TB, Mitchell SR, Li T, Morgan ET. Modulation of drug metabolism in infectious and inflammatory diseases. Drug Metab Rev. 1999;31(1):29-41.

52. Sukhai M, Piquette-Miller M. Regulation of the multidrug resistance genes by stress signals. J Pharm Pharm Sci. 2000;3(2):268-280.

53. Trotter JF, Osborne JC, Heller M, Christians U. Effect of hepatitis $\mathrm{C}$ infection on tacrolimus doses and blood levels in liver transplantation recipients. Aliment Pharmacol Ther. 2005;22(1):37-44.

54. Salm P, Warnholtz C, Boyd J, Arabshahi L, Marbach P, Taylor PJ. Evaluation of a fluorescent polarization immunoassay for whole blood everolimus determination using samples from renal transplant recipients. Clin Biochem. 2006;39(7):732-738.

55. Strom T, Haschke M, Boyd J, et al. Crossreactivity of isolated everolimus metabolites with the Innofluor Certican immunoassay for therapeutic drug monitoring of everolimus. Ther Drug Monit. 2007; 29(6):743-749

56. Korecka M, Shaw LM. Review of the newest HPLC methods with mass spectrometry detection for determination of immunosuppressive drugs in clinical practice. Ann Transplant. 2009;14(2):61-72.

57. United Kingdom National External Quality Assessment Service. Available at: http://www.ukneqas.org.uk/content/Pageserver.asp. Accessed on March 31, 2011

58. Hausen B, Boeke K, Berry GJ, Segarra IT, Christians U, Morris RE. Suppression of acute rejection in allogeneic rat lung transplantation: A study of the efficacy and pharmacokinetics of rapamycin derivative (SDZ RAD) used alone and in combination with a microemulsion formulation of cyclosporine. J Heart Lung Transplant. 1999;18(2):150-159.

59. Cole OJ, Shehata M, Rigg KM. Effect of SDZ RAD on transplant arteriosclerosis in the rat aortic model. Transplant Proc. 1998; 30(5):2200-2203.

60. Schuurman HJ, Ringers J, Schuler W, Slingerland W, Jonker M. Oral efficacy of the macrolide immunosuppressant SDZ RAD and of cyclosporine microemulsion in cynomolgus monkey kidney allotransplantation. Transplantation. 2000;69(5):737-742.

61. Viklicky O, Zou H, Muller V, Lacha J, Szabo A, Heemann U. SDZ-RAD prevents manifestation of chronic rejection in rat renal allografts. Transplantation. 2000;69(4):497-502.

62. Schuurman HJ, Pally C, Weckbecker G, Schuler W, Bruns C. SDZ RAD inhibits cold ischemia-induced vascular remodeling. Transplant Proc. 1999;31(1-2):1024-1025

63. Serkova N, Christians U. Transplantation: Toxicokinetics and mechanisms of toxicity of cyclosporine and macrolides. Curr Opin Investig Drugs. 2003;4(11):1287-1296.

64. Vitko S, Margreiter R, Weimar W, et al. Everolimus (Certican) 12-month safety and efficacy versus mycophenolate mofetil in de novo renal transplant recipients. Transplantation. 2004;78(10):1532-1540.

65. Vitko S, Margreiter R, Weimar W, et al. Three-year efficacy and safety results from a study of everolimus versus mycophenolate mofetil in de novo renal transplant patients. Am J Transplant. 2005;5(10):2521-2530.

66. Lorber MI, Mulgaonkar S, Butt KM, et al. Everolimus versus mycophenolate mofetil in the prevention of rejection in de novo renal transplant recipients: A 3-year randomized, multicenter, phase III study. Transplantation. 2005;80(2):244-252.

67. Podder H, Stepkowski SM, Napoli KL, et al. Pharmacokinetic interactions augment toxicities of sirolimus/cyclosporine combinations. J Am Soc Nephrol. 2001;12(5):1059-1071.

68. Nashan B, Curtis J, Ponticelli C, Mourad G, Jaffe J, Haas T. Everolimus and reduced-exposure cyclosporine in de novo renal-transplant recipients: A three-year phase II, randomized, multicenter, open-label study. Transplantation. 2004;78(9):1332-1340. 
69. Vitko S, Tedesco H, Eris J, et al. Everolimus with optimized cyclosporine dosing in renal transplant recipients: 6-month safety and efficacy results of two randomized studies. Am J Transplant. 2004;4(4):626-635.

70. Tedesco-Silva H Jr, Vitko S, Pascual J, et al. 12-month safety and efficacy of everolimus with reduced exposure cyclosporine in de novo renal transplant recipients. Transpl Int. 2007;20(1):27-36.

71. Tedesco Silva H Jr, Cibrik D, Johnston T, et al. Everolimus plus reducedexposure CsA versus mycophenolic acid plus standard-exposure CsA in renal-transplant recipients. Am J Transplant. 2010;10(6):1401-1413.

72. Budde K, Becker T, Arns W, et al. Everolimus-based, calcineurin-inhibitor-free regimen in recipients of de-novo kidney transplants: An openlabel, randomised, controlled trial. Lancet. 2011;377(9768):837-847.

73. Wu O, Levy AR, Briggs A, Lewis G, Jardine A. Acute rejection and chronic nephropathy: A systematic review of the literature. Transplantation. 2009;87(9):1330-1339.

74. Sijpkens YW, Doxiadis, II, Mallat MJ, et al. Early versus late acute rejection episodes in renal transplantation. Transplantation. 2003;75(2):204-208.

75. Mendez R, Gonwa T, Yang HC, Weinstein S, Jensik S, Steinberg S A prospective, randomized trial of tacrolimus in combination with sirolimus or mycophenolate mofetil in kidney transplantation: Results at 1 year. Transplantation. 2005;80(3):303-309.

76. Ciancio G, Burke GW, Gaynor JJ, et al. A randomized long-term trial of tacrolimus/sirolimus versus tacrolimums/mycophenolate versus cyclosporine/sirolimus in renal transplantation: Three-year analysis Transplantation. 2006;81(6):845-852.

77. Vitko S, Wlodarczyk Z, Kyllonen L, et al. Tacrolimus combined with two different dosages of sirolimus in kidney transplantation: Results of a multicenter study. Am J Transplant. 2006;6(3):531-538.

78. Meier-Kriesche HU, Schold JD, Srinivas TR, Howard RJ, Fujita S, Kaplan B. Sirolimus in combination with tacrolimus is associated with worse renal allograft survival compared with mycophenolate mofetil combined with tacrolimus. Am J Transplant. 2005;5(9):2273-2280.

79. Gralla J, Wiseman AC. Tacrolimus/sirolimus versus tacrolimus/ mycophenolate in kidney transplantation: Improved 3-year graft and patient survival in recent era. Transplantation. 2009;87(11):1712-1719.

80. Rostaing L, Kamar N. mTOR inhibitor/proliferation signal inhibitors: Entering or leaving the field? J Nephrol. 2010;23(2):133-142.

81. Kasiske BL, de Mattos A, Flechner SM, et al. Mammalian target of rapamycin inhibitor dyslipidemia in kidney transplant recipients. $\mathrm{Am}$ J Transplant. 2008;8(7):1384-1392.

82. Augustine JJ, Knauss TC, Schulak JA, Bodziak KA, Siegel C, Hricik DE. Comparative effects of sirolimus and mycophenolate mofetil on erythropoiesis in kidney transplant patients. Am J Transplant. 2004;4(12):2001-2006.

83. Augustine JJ, Rodriguez V, Padiyar A, Bodziak KA, Schulak JA, Hricik DE. Reduction in erythropoietin resistance after conversion from sirolimus to enteric coated mycophenolate sodium. Transplantation. 2008;86(4):548-553.

84. Maiorano A, Stallone G, Schena A, et al. Sirolimus interferes with iron homeostasis in renal transplant recipients. Transplantation. 2006;82(7):908-912

85. Sanchez Fructuoso A, Calvo N, Moreno MA, Giorgi M, Barrientos A. Study of anemia after late introduction of everolimus in the immunosuppressive treatment of renal transplant patients. Transplant Proc. 2007;39(7):2242-2244.

86. Letavernier E, Legendre C. mToR inhibitors-induced proteinuria: Mechanisms, significance, and management. Transplant Rev (Orlando). 2008;22(2):125-130.

87. Franco AF, Martini D, Abensur H, Noronha IL. Proteinuria in transplant patients associated with sirolimus. Transplant Proc. 2007;39(2):449-452.

88. Ruiz JC, Campistol JM, Sanchez-Fructuoso A, et al. Early sirolimus use with cyclosporine elimination does not induce progressive proteinuria. Transplant Proc. 2007;39(7):2151-2152.

89. Straathof-Galema L, Wetzels JF, Dijkman HB, Steenbergen EJ, Hilbrands LB. Sirolimus-associated heavy proteinuria in a renal transplant recipient: Evidence for a tubular mechanism. Am J Transplant. 2006;6(2):429-433.
90. Van den Akker JM, Wetzels JF, Hoitsma AJ. Proteinuria following conversion from azathioprine to sirolimus in renal transplant recipients. Kidney Int. 2006;70(7):1355-1357.

91. Biancone L, Bussolati B, Mazzucco G, et al. Loss of nephrin expression in glomeruli of kidney-transplanted patients under m-TOR inhibitor therapy. Am J Transplant. 2010;10(10):2270-2278.

92. McTaggart RA, Tomlanovich S, Bostrom A, Roberts JP, Feng S Comparison of outcomes after delayed graft function: Sirolimus-based versus other calcineurin-inhibitor sparing induction immunosuppression regimens. Transplantation. 2004;78(3):475-480.

93. Durrbach A, Rostaing L, Tricot L, et al. Prospective comparison of the use of sirolimus and cyclosporine in recipients of a kidney from an expanded criteria donor. Transplantation. 2008;85(3):486-490.

94. Stallone G, Di Paolo S, Schena A, et al. Addition of sirolimus to cyclosporine delays the recovery from delayed graft function but does not affect 1-year graft function. J Am Soc Nephrol. 2004;15(1): 228-233.

95. Simon JF, Swanson SJ, Agodoa LY, Cruess DF, Bohen EM, Abbott KC. Induction sirolimus and delayed graft function after deceased donor kidney transplantation in the United States. Am J Nephrol. 2004;24(4):393-401.

96. Dantal J, Berthoux F, Moal MC, et al. Efficacy and safety of de novo or early everolimus with low cyclosporine in deceased-donor kidney transplant recipients at specified risk of delayed graft function: 12-month results of a randomized, multicenter trial. Transpl Int. 2010;23(11):1084-1093.

97. Langer RM, Kahan BD. Incidence, therapy, and consequences of lymphocele after sirolimus-cyclosporine-prednisone immunosuppression in renal transplant recipients. Transplantation. 2002;74(6): 804-808.

98. Valente JF, Hricik D, Weigel K, et al. Comparison of sirolimus versus mycophenolate mofetil on surgical complications and wound healing in adult kidney transplantation. Am J Transplant. 2003; 3(9):1128-1134.

99. Troppmann C, Pierce JL, Gandhi MM, Gallay BJ, McVicar JP, Perez RV. Higher surgical wound complication rates with sirolimus immunosuppression after kidney transplantation: A matched-pair pilot study. Transplantation. 2003;76(2):426-429.

100. Dean PG, Lund WJ, Larson TS, et al. Wound-healing complications after kidney transplantation: A prospective, randomized comparison of sirolimus and tacrolimus. Transplantation. 2004;77(10):1555-1561.

101. Penn I. Cancers complicating organ transplantation. $N$ Engl J Med. 1990;323(25):1767-1769.

102. Agraharkar ML, Cinclair RD, Kuo YF, Daller JA, Shahinian VB. Risk of malignancy with long-term immunosuppression in renal transplant recipients. Kidney Int. 2004;66(1):383-389.

103. Morath C, Mueller M, Goldschmidt H, Schwenger V, Opelz G, Zeier M. Malignancy in renal transplantation. J Am Soc Nephrol. 2004;15(6):1582-1588.

104. Kasiske BL, Snyder JJ, Gilbertson DT, Wang C. Cancer after kidney transplantation in the United States. Am J Transplant. 2004;4(6): 905-913.

105. Vignot S, Faivre S, Aguirre D, Raymond E. mTOR-targeted therapy of cancer with rapamycin derivatives. Ann Oncol. 2005;16(4) 525-537.

106. Campistol JM, Eris J, Oberbauer R, et al. Sirolimus therapy after early cyclosporine withdrawal reduces the risk for cancer in adult renal transplantation. J Am Soc Nephrol. 2006;17(2):581-589.

107. Krueger DA, Care MM, Holland K, et al. Everolimus for subependymal giant-cell astrocytomas in tuberous sclerosis. $N$ Engl J Med. 2010; 363(19):1801-1811.

108. Motzer RJ, Escudier B, Oudard S, et al. Efficacy of everolimus in advanced renal cell carcinoma: A double-blind, randomised, placebocontrolled phase III trial. Lancet. 2008;372(9637):449-456.

109. Krams SM, Martinez OM. Epstein-Barr virus, rapamycin, and host immune responses. Curr Opin Organ Transplant. 2008;13(6): 563-568. 
110. Haydar AA, Denton M, West A, Rees J, Goldsmith DJ. Sirolimus-induced pneumonitis: Three cases and a review of the literature. Am J Transplant. 2004;4(1):137-139.

111. Champion L, Stern M, Israel-Biet D, et al. Brief communication: Sirolimus-associated pneumonitis: 24 cases in renal transplant recipients. Ann Intern Med. 2006;144(7):505-509.

112. Langer RM, Van Buren CT, Katz SM, Kahan BD. De novo hemolytic uremic syndrome after kidney transplantation in patients treated with cyclosporine-sirolimus combination. Transplantation. 2002;73(5):756-760.

113. Fortin MC, Raymond MA, Madore F, et al. Increased risk of thrombotic microangiopathy in patients receiving a cyclosporin-sirolimus combination. Am J Transplant. 2004;4(6):946-952.

114. Crew RJ, Radhakrishnan J, Cohen DJ, et al. De novo thrombotic microangiopathy following treatment with sirolimus: Report of two cases. Nephrol Dial Transplant. 2005;20(1):203-209.
115. Otton J, Hayward CS, Keogh AM, Glanville AR, Macdonald PS. Everolimus-associated pneumonitis in 3 heart transplant recipients. J Heart Lung Transplant. 2009;28(1):104-106.

116. Mahe E, Morelon E, Lechaton S, et al. Cutaneous adverse events in renal transplant recipients receiving sirolimus-based therapy. Transplantation. 2005;79(4):476-482.

117. Desai N, Heenan S, Mortimer PS. Sirolimus-associated lymphoedema: Eight new cases and a proposed mechanism. Br J Dermatol. 2009; 160(6):1322-1326.

118. Strom T, Haschke M, Zhang YL, et al. Identification of everolimus metabolite patterns in trough blood samples of kidney transplant patients. Ther Drug Monit. 2007;29(5):592-599.

\section{Publish your work in this journal}

Transplant Research and Risk Management is an international, peerreviewed open access journal focusing on all aspects of transplantation and risk management to achieve optimal outcomes in the recipient improving survival and quality of life. The journal welcomes submitted papers covering original research, basic science, clinical studies, reviews \& evaluations, guidelines, expert opinion and commentary, case reports and extended reports. The manuscript management system is completely online and includes a very quick and fair peer-review system, which is all easy to use. Visit http://www.dovepress.com/ testimonials.php to read real quotes from published authors. 